\section{К ВОПРОСУ ДОЛГОСРОЧНОГО ПРОГНОЗИРОВАНИЯ ХОДА ЭЛЕМЕНТОВ ПОГОДЫ В ТЕЧЕНИЕ МЕСЯЦА}

\section{Е.А. Полянская, С.В. Морозова, Г.А. Пужлякова,} Л.М. Фетисова

\author{
Саратовский государственный университет, \\ кафедра метеорологии и климатологии, \\ E-mail: nfetisova@gmail.com
}

В настоящей работе приводятся результаты разработки региональной модели долгосрочного прогнозирования изменения характера погоды в течение месяца, а именно дней резких перепадов средней суточной температуры воздуха и осадков с конкретизацией даты их выпадения для Саратовской области. Подробно представлены вид прогностической продукции и оправдываемость данного способа детализированного долгосрочного прогнозирования хода элементов погоды в течение месяца.

To the Question of Long-range Forecast of Weather Elements Development During a Month

\section{E.A. Polyanskaya, S.V. Morosova, G.A. Pushliakova, L.M. Fetisova}

The work presents the results of the elaborating of the regional system of long-range forecast of the weather character's changing during a month, exactly on the days with sudden changes of average day-night air temperature and precipitation with the concretization of the falling date for the Saratov region. The sort of forecasting production and justification of the given way of the long-range forecast of weather elements' development during a month are thoroughly shown.

Долгосрочное прогнозирование хода элементов погоды в течение месяца представляет собой сложную и далекую от разрешения научную проблему. Численные методы довольно успешно прогнозируют погоду и ее изменения на срок 5-10 дней, далее их применение ограничивается пределом предсказуемости атмосферных процессов. Поэтому разработка надежных методов прогнозирования погоды и ее изменений на более длительные промежутки времени является весьма актуальной.

В настоящей работе приводятся результаты разработки региональной модели долгосрочного прогнозирования изменения характера погоды в течение месяца, а именно дней резких перепадов средней суточной температуры воздуха и осадков с конкретизацией даты их выпадения для Саратовской области.

В основу модели положен принцип «плавающего аналога», предложенный В.Ф. Мартазиновой [1], который, в отличие от традиционного понятия аналогичности, требует не географического совпадения аналогичного и текущего синоптических процессов, а требует лишь наилучшего геометри-

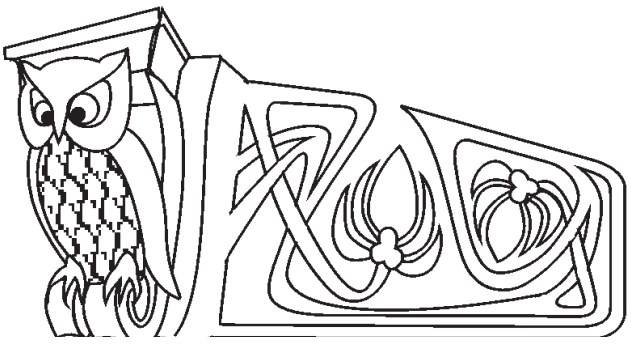

ческого подобия фигур планетарной высотной фронтальной зоны или наилучшего совпадения знака барического поля у поверхности Земли. Такой подход позволил выявить двухмесячную квазипериодичность атмосферных процессов Северного полушария и существенно расширить временные возможности составления детализированных долгосрочных прогнозов погоды.

Информационной базой для реализации модели являются данные о давлении воздуха на уровне моря в узлах регулярной сетки с шагом по широте и долготе $5^{\circ}$ на пространстве первого естественного синоптического района, ограниченного меридианами $30^{\circ}$ з.д. , $70^{\circ}$ в.д. и параллелями $40^{\circ}$ и $70^{\circ}$ с.ш.

На первом этапе реализации модели проводится объективный анализ барических полей, обусловливающих сильные осадки (более 3,5 мм), и барических полей, определяющих резкие похолодания и потепления в каждом месяце с целью выявления наиболее информативных «эталонных» полей на основе ранжирования матриц евклидова расстояния по формулам (1)-(2):

$$
\begin{gathered}
\tilde{N}(i, \delta)=\frac{1}{q} \sqrt{\sum_{j=1}^{q}(x(i, j)-x(ð, j))^{2}}, \\
i, p=1, k ; \\
q=147,
\end{gathered}
$$

где $C(i, p)$ - параметр близости (удаленности) между $i$-м и $p$-м барическими полями;

$x(i, j), x(p, j)$ - давление в $j$-й точке $i$-го и $p$-го полей;

$k$ - число выбранных полей;

$q$ - число узлов регулярной сетки;

$$
S(i)=\frac{1}{k} \sum_{p=1}^{k} C(i, p) .
$$

По наименьшим значениям параметров $C(i, p)$ и $S(i)$ выделяется эталонное поле, обладающее наибольшей схожестью с остальными в исходной выборке при однотипных процессах [2].

На втором этапе осуществляется подбор аналогов выявленным эталонным полям на основе двухмесячной квазипериодичности атмосферных процессов Северного полушария по методу «плавающего аналога», допускающего смещение аналоговых полей относительно эталонных на $\pm 15^{\circ}$ по меридиану $\pm 60^{\circ}$ по параллели. Степень 
аналогичности барических полей оценивается с помощью показателя $\rho$ по формуле

$$
p=\frac{n_{+}-n_{-}}{N}
$$

где $n_{+}-$число узлов, в которых знак отклонения давления сравниваемых полей совпадает; $n$-число узлов, в которых знак отклонения давления сравниваемых полей противоположный; $N$ - общее число узлов регулярной сетки.

Найденные таким образом аналоговые поля являются предикторами для барических полей, обусловливающих выпадение осадков в течение месяца, и полей, определяющих резкие перепады средней суточной температуры воздуха. Заблаговременность такого прогноза составляет один месяц [3].

Вид прогностической продукции представлен в таблице, где в качестве примера приведен прогноз на июнь 2005 г., составленный 1 мая 2005 года. Заметим, что резкие повышения (понижения) средней суточной температуры представлены волнами тепла (холода). Под волной тепла (холода) понимается соответствующее изменение средней суточной температуры воздуха на $5^{\circ} \mathrm{C}$ и более, продолжавшееся не менее двух дней подряд.

Прогноз резких изменений погоды в июне 2005 года

\begin{tabular}{|c|c|c|}
\hline \multicolumn{2}{|c|}{ Ожидаемые даты } \\
\hline Волн тепла & Волн холода & Выпадения осадков \\
\hline $11-15$ & $5-6$ & $1-2$ \\
\hline $26-27$ & $22-25$ & $14-15$ \\
\hline & & $22-25$ \\
\hline
\end{tabular}

Таким образом, в июне 2005 г. экстремумы волн тепла ожидались 11-15 и 26-27 июня, экстремумы волн холода - 5-6 и 22-25 июня; выпадение осадков предполагалось 1-2, 14-15 и 22-25 июня. При проверке волна тепла (холода) считалась оправдавшейся, если наблюдалось повышение (понижение) средней суточной температуры воздуха не менее чем на $5^{\circ} \mathrm{C}$ и время осуществления экстремума волны либо совпадало с днем прогноза, либо сдвиг не превышал \pm 2 дня. Прогноз дней с осадками считался оправдавшимся, если факт их выпадения отстоял не более чем на два дня от ожидаемой даты их выпадения и суточное количество составляло более 0,3 мм. Изменчивость средней суточной температуры воздуха и суточное количество осадков в июне 2005 г. представлены на рисунке.

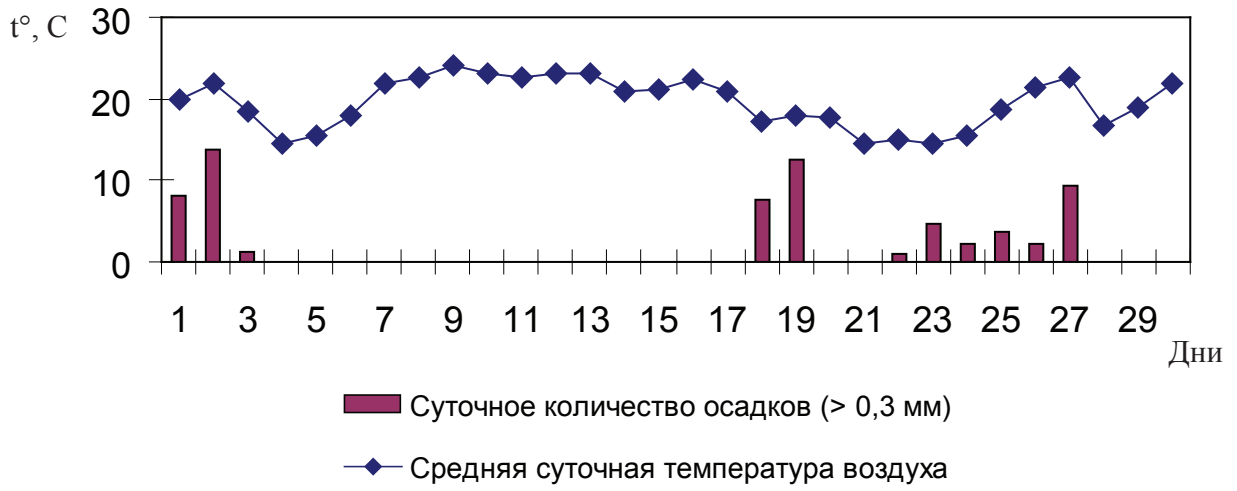

Временная изменчивость метеовеличин в июне 2005 г. в Саратове

Как видно из рисунка, в ходе средней суточной температуры воздуха в июне 2005 г. четко прослеживаются по два периода повышения и понижения температуры. Экстремумы похолоданий фактически наблюдались 4 и 23 июня, что соответствовало прогнозируемому. Ожидаемый экстремум первой волны тепла оказался смещенным на 2 дня по отношению к фактическому. Вторая же волна тепла осуществилась с абсолютной точностью. Осадки, выпавшие в начале и конце месяца, также соответствовали ожидаемым датам их выпадения. Только осадки, ожидаемые 14-15 июня, выпали не в середине, а в конце второй декады месяца, т.е. прогноз осадков на 14-15 июня не оправдался. Таким образом, на июнь 2005 г. довольно успешно спрогнозирован ход элементов погоды в течение месяца.

Оправдываемость прогнозов за период 2000-2004 гг. составила $69 \%$ для дат резких потеплений и похолоданий в течение месяца, $62 \%$ для дат выпадения осадков. 
Таким образом, учитывая довольно жесткие критерии оправдываемости и достаточно большую заблаговременность, можно говорить о перспективности детализированного долгосрочного прогнозирования экстремумов метеорологических величин и хода элементов погоды в течение месяца.

Имеющаяся информационная база и программное обеспечение позволяют решать аналогичные задачи для сопредельных регионов.

Работа выполнена при финансовой поддержке Научной программы Министерства образования РФ «Университеты России» проект 8.5.9 «Метод и автоматизированная технология долгосрочного прогноза сильных осадков теплого периода» (грант УР.08.01.030).

\section{Библиографический список}

1. Мартазинова В.Ф., Сологуб Т.А. Определение квазипериодичности атмосферных процессов на Северном полушарии с помощью метода «плавающий аналог» // Тр. УкрНИГМИ. 1986. Вып. 219. С. 37-42.

2. Морозова С.В., Пужлякова Г.А. Эталонные поля давления интенсивных волн тепла и холода летом и зимой в Саратовской области // Анализ и прогноз гидрометеорологических элементов. Вопросы охраны атмосферы. Пермь, 1997. C. 25-30.

3. Морозова С.В., Полянская Е.А. К вопросу прогноза экстремумов метеорологических величин // Перспективы развития Волжского региона: Материалы Всерос. заочной конф. Тверь, 2003. С. 69-70.

\section{ИЗМЕНЕНИЕ ЭТНИЧЕСКОГО СОСТАВА НАСЕЛЕНИЯ ОБЛАСТИ И ТОЛЕРАНТНОСТЬ СТУДЕНТОВ САРАТОВСКОГО ГОСУНИВЕРСИТЕТА}

\section{С.В.Уставщикова}

Саратовский государственный университет, кафедра экономической географии E-mail: Reena.1.@yandex.ru

В статье рассмотрены изменения в этническом составе населения Саратовской области за 1989-2002 годы. Выявлена роль этнической миграции в данных изменениях. Отмечается рост в области народов Кавказа и Средней Азии. Изучение отношения к мигрантам выявило: довольно высокий потенциал толерантности студентов к данной категории населения; проявляется беспокойство по поводу конкуренции за рабочие места; возможность конфликта на «поведенческой» основе, неприемлемой в принимающем обществе с мигрантами из республик Закавказья; обеспокоенность демографической проблемой в РФ, миграционной политикой в стране.

Change of Ethnic Composition of the Population of the Region, and Tolerance of the Students of the Saratov State University

\section{S.V. Ustavschikova}

In the article change of the ethnic composition of the popularity of the Saratov region at the period from 1989 to 2002 are considering. The author shows as the role of the ethnic migration in given changes. In the region a number of people from the Caucasuc and Central Asia are growing. It is revealed, that: students are rather tolerant to emigrants; they are worried about the competition for job vacancy; conflict at the cultural ground is possible; they worried about demographical situation in the Russian Federation and its emigration policy.

В Саратовской области проживают более 110 этносов. Это результат исторического процесса заселения и освоения Саратовской земли, этнических процессов (этнического разделения и этнического объединения), этнической дифференциации

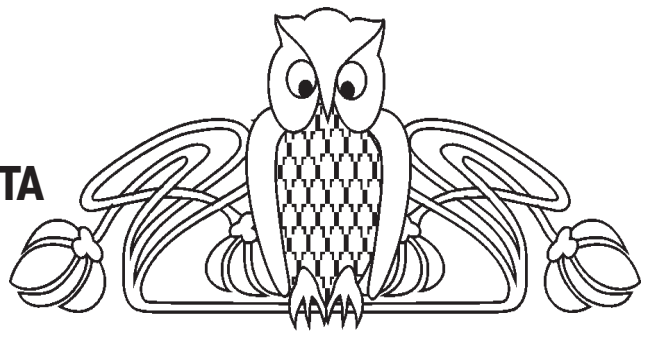

естественного воспроизводства и современных миграционных процессов.

Саратовская область является одним из принимающих мигрантов регионов России. По оценке областной миграционной службы, с конца 1990-х гг. по 2005 г. в Саратовскую область прибыло примерно 260 тыс. человек, что составляет почти $10 \%$ от численности населения области. Это достаточно большой показатель с точки зрения влияния миграции на все сферы жизнедеятельности территории, в том числе и на сферу межнациональных отношений.

Область привлекательна для мигрантов, она обладает большим производственным и научным потенциалом, развитой инфраструктурой. Привлекательность губернии обусловлена также относительной социально-политической стабильностью, комфортными климатическими условиями, значительным потенциалом для расселения населения в сельской местности (низкой плотностью сельского населения, значительным числом уже опустевших населенных пунктов - по переписи 2002 г. их 60, а также находящихся на грани исчезновения).

Складывающаяся демографическая ситуация в области, как и в целом по стране, объективно требует дополнительного привлечения трудовых ресурсов для обеспечения экономики региона. Население области сокращается. Если на момент переписи 2002 г. численность населения составляла 2668,3 тыс. человек, то на начало 2005 г. - уже 2625,7 тысяч. При этом, согласно данным статистики, после пика миграции из новых независимых 